Ethiopian Journal of Environmental Studies \& Management 10(1): 101 - 111, 2017.

ISSN:1998-0507

doi: http://dx.doi.org/10.4314/ejesm.v10i1.10

Submitted: October 19, 2016

Accepted: January 25, 2017

\title{
EFFECT OF FOREST COVER ON CLIMATE WITH IMPLICATIONS FOR AGRICULTURE, ANIMAL HUSBANDRY AND WATER PROVISIONS
}

\author{
ANTENEH SHIMELIS \\ Department of Zoological Sciences, Addis Ababa University, Ethiopia \\ Email: antreraptor@yahoo.co.uk
}

\begin{abstract}
Meta data gleaned from the literature was modeled to determine one of the functions of forests in Ethiopia to explain their reported key role in boosting food production. This refers to their function in regulating climate across four forested regions of Ethiopia. Forest cover significantly explained variations in averages of precipitation and temperature which was also shown to have significant effects on food production, availability of surface water and ground water. The results showed forests are responsible for high precipitation and cooler climate which were shown to be the requirements for high productivity of crops and animal husbandry which are dependent upon the availability of surface and ground water that are respectively affected positively and negatively by the levels of precipitation and temperature. The conclusion from the paper is deforestation enhances the warming of the climate with consequences such as significant decline in food production and availability of both surface and ground water. Forest conservation is thus vital for the economy ensuring not only humans survive but flourish also.
\end{abstract}

Key Words: Climate, Forest Cover, Crop Production, Livestock Production, Surface Water, Ground Water

\section{Introduction}

The economic benefits from pristine natural ecosystems such as forests have been consistently emphasized and evidence reported by various workers around the world (Constanza et al., 2006; de Groot et al., 2002; de Groot et al., 2010; Shimelis 2016). Shimelis (2016) have substantiated the economic values of Ethiopia's forests through the depiction of their effects on productivity of agriculture and animal husbandry. Furthermore evidence was presented regarding the important role played by forests in enhancing availability of both surface and ground water which themselves had significant effects on productivity of agriculture and animal husbandry.

There is a consensus amongst the largest majority of ecologists of this world that climate change is a very important global problem (Smit and Skinner, 2002; Sutherland et al., 2010, Karl et al., 1993) and forests through the sequestration of carbon linked green house gases play a major role in lessening it and also mitigating it (Sutherland et al., 2010). To this effect climate centered conservation 
initiatives and also calls for active engagement in mitigation of climatic warming cite such convictions of the roles of the globe's forests (Sutherland et al., 2010). It may be true that the forests considered in Shimelis (2016) do have such an effect and highly interrelated to this, they may have climate centered functions which help explain why they have boosted productivity in sectors critical to humans.

After the availing of the listed evidences question remained by what manner of functional processes forests caused such positive changes in modes of production critical for the survival and also flourishing of human beings. The principal hypothesis of this paper is forests significantly affect climate, particularly temperature and precipitation, which themselves are important predictors of agricultural productivity, outputs of animal husbandry and availability of surface and ground water. To verify the validities of this hypothesis meta data which was previously published was gleaned and modeled.

\section{Methods}

The study area encompasses four regions in Ethiopia namely Amhara, Oromiya, Southern Nations and People and Tigray. The four regions have differing extents of cloud afromontane forest (Shimelis, 2016) shared and unique important characteristics of the four regions are already reported and are parts of the existing body of peer-reviewed literature (Shimelis et al., 1996, Shimelis, 2016).

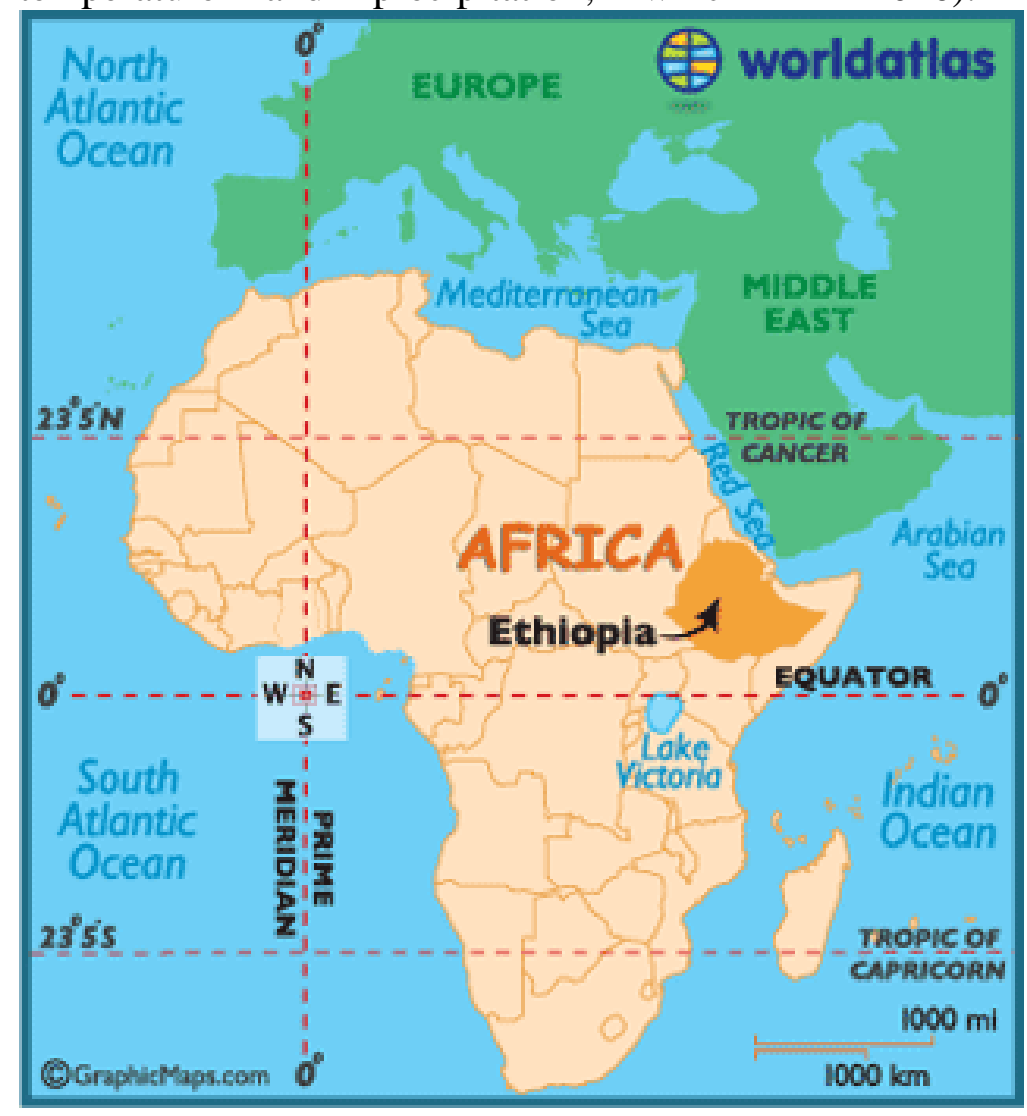

Figure1: The location of Ethiopia which is the study area relative to the three continents 
Meta data from various sources on forest cover (Shimelis et al., 1996, EWNHS, 2001), regional crop output, regional crop and livestock output (Ehui et al., 2001), and climate (Aulachew et al., 2007) was gleaned and through successive univariate linear regression modeling the regulatory effects of forest cover on the climatic components of the regions was explored with the effect that the latter's contribution to food production and water provisions was investigated.

In a similar fashion to Shimelis (2016) data on all variables except climate was used in the modeling process. Data on averages of precipitation and temperature for each of the four regions was calculated from random and representative locations on the cartographic climatic report and these were linearly regressed against the rest as found appropriate.

\section{Results \\ The Effects of Forest Cover on Climate}

The amount of rainfall that a region receives in Ethiopia is significantly $(\mathrm{P}<$ 0.01 ) a function of how well the region is covered with forests. There was a positive increasing effect of forest cover on precipitation which is the amount of rainfall that a region was observed to have had (Figure 2). The predicted linear best fit line in this model explained more than $95 \%$ of the observations made on the response variable.

The second part of figure 2 indicates there is a significant cooling effect of forests on the climate of the regions considered as there was significant $(\mathrm{P}<$ $0.01)$ negative relationship between forest cover and average temperature of the regions. Here the model's predicted best fit line explained more than $77 \%$ of the variation in observations of regional average temperature. 
Effect of Forest Cover on Climate with Implications for Agriculture.................ANTENEH

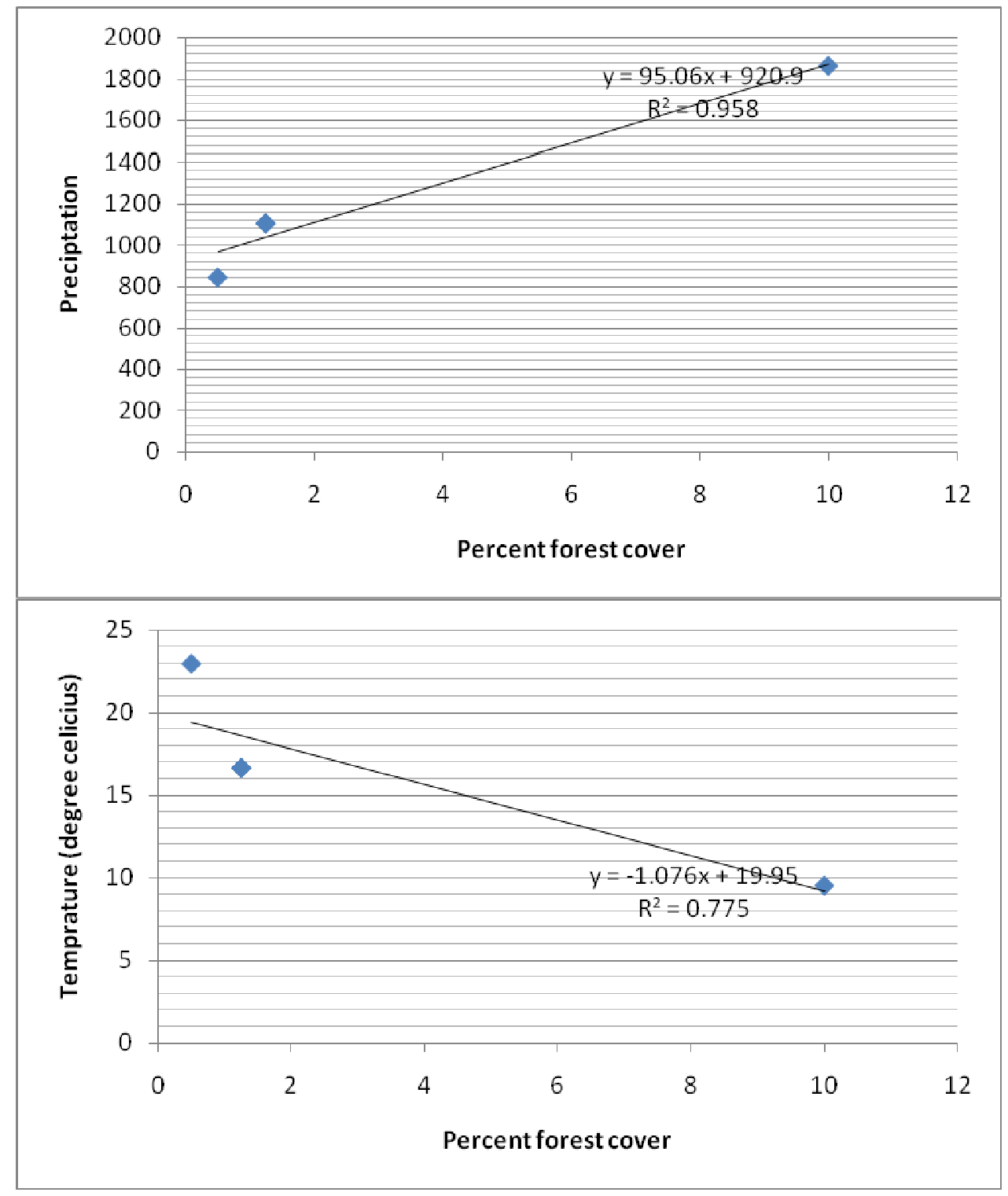

Figure 2: The effects of forest cover on the climate of forested regions of Ethiopia

\section{Sensitivities of Crops to Climate}

As indicated in figure 3 the level of precipitation had significant $(\mathrm{P}<0.01)$ increasing effects on crop output. The predicted best fit line in the model explained more than $88 \%$ of the variation in crop output observations.
Figure 3 again shows how crops are sensitive to temperature. Significant $(\mathrm{P}<$ 0.01) decline in crop output was observed as the climate increasingly warmed in a model the best fit line of which explained more than $97 \%$ of the variation in the data set. 


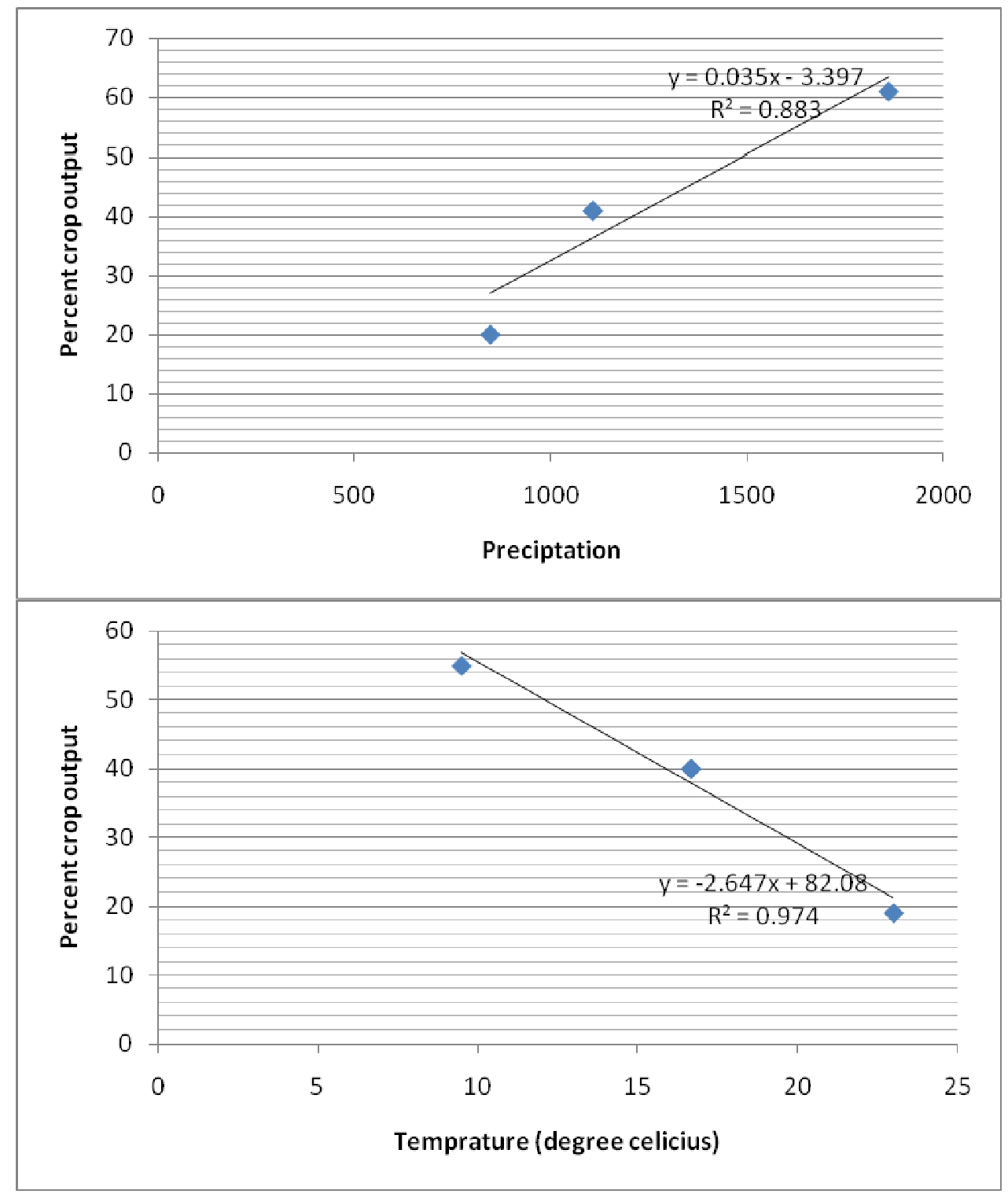

Figure 3: The effects of climatic variables on percent crop output across regions

\section{Sensitivities of Crop Plus Livestock Output to Climate}

Figure 4 indicates there was significant positive effect of the rain that was fallen across regions on the crop and livestock output. The model's best fit explained more than $81 \%$ of the variation in the observed data set of the crop and livestock output.
As the temperature component of the climate warmed there was significant decline in the crop and livestock output (Figure 4). The model's best fit explained more than $97 \%$ of the variation in the observed data set. 
Effect of Forest Cover on Climate with Implications for Agriculture.................ANTENEH

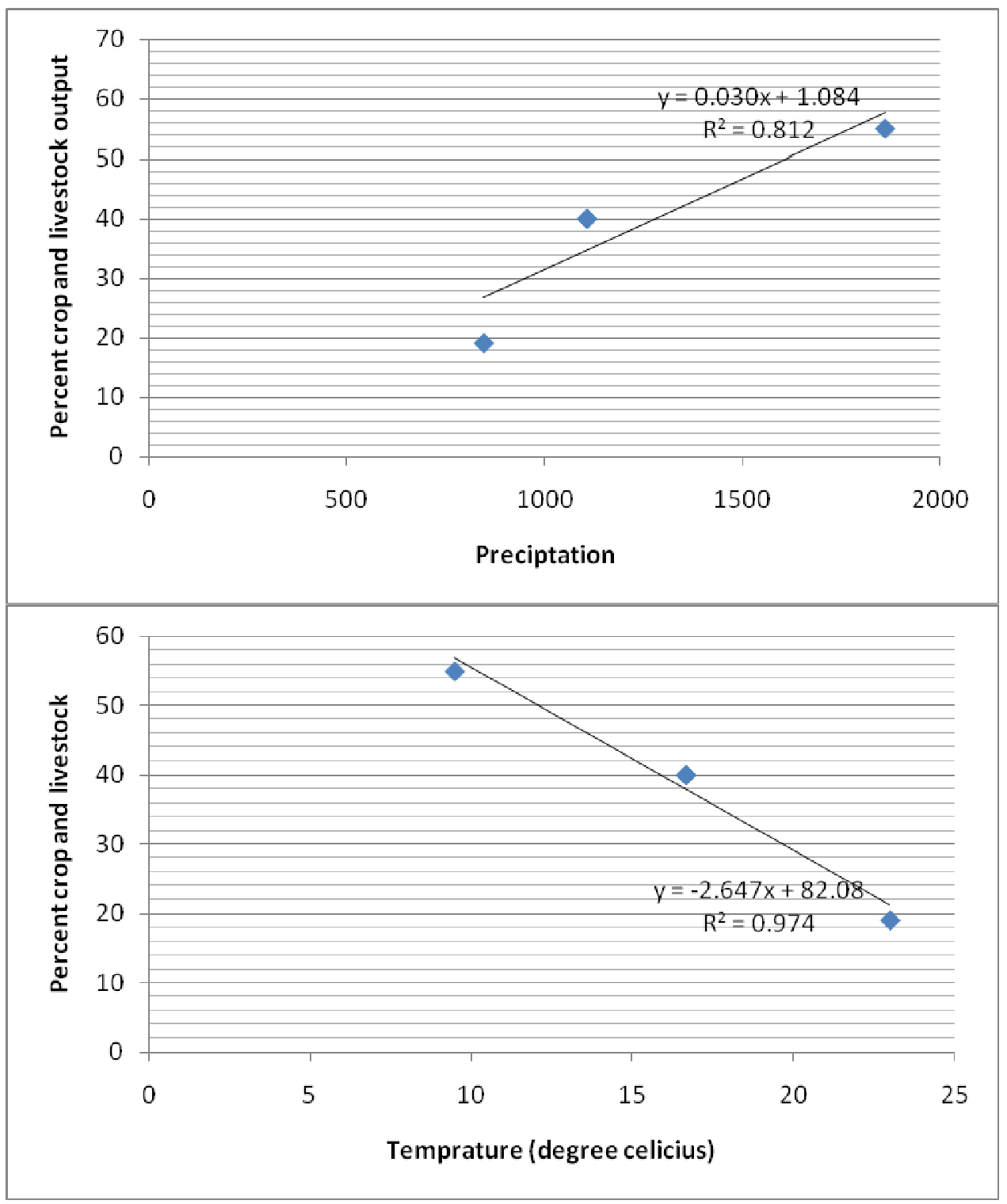

Figure 4: Response of crop and livestock output to climate across the regions considered

Sensitivities of Surface Water to Climate

As result of increase in rainfall there was significant $(\mathrm{P}<0.01)$ increase in the available surface water across regions
(Figure 5). The model's best fit line explained more than $99 \%$ of the variation in the observed data set for surface water volume. 

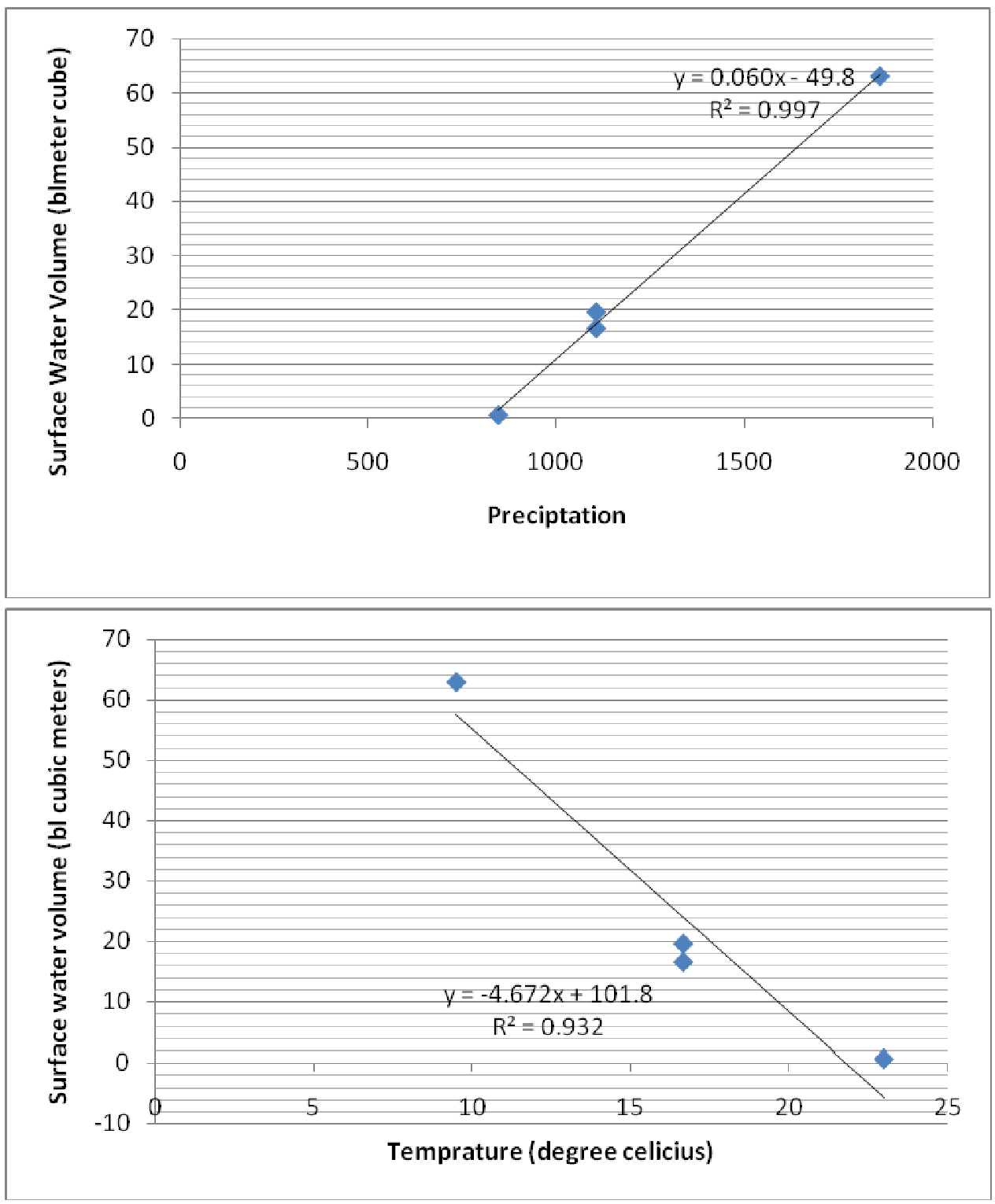

Figure 5: Sensitivities of the available surface water to levels of precipitation and temperature

Surface water significantly $(\mathrm{P}<0.01)$ declined as the climate had warmed across regions (Figure 5). The best fit line of the model explained more than $93 \%$ of the variation in the data set.
Sensitivities of Ground Water to Climate

Figure 6 shows there was a significant $(\mathrm{P}<0.01)$ increase in ground water volume across regions as the amount of rainfall increased. The best fit line of the model explained more than $97 \%$ of the variation in observations of ground water volume. 
Effect of Forest Cover on Climate with Implications for Agriculture.................ANTENEH

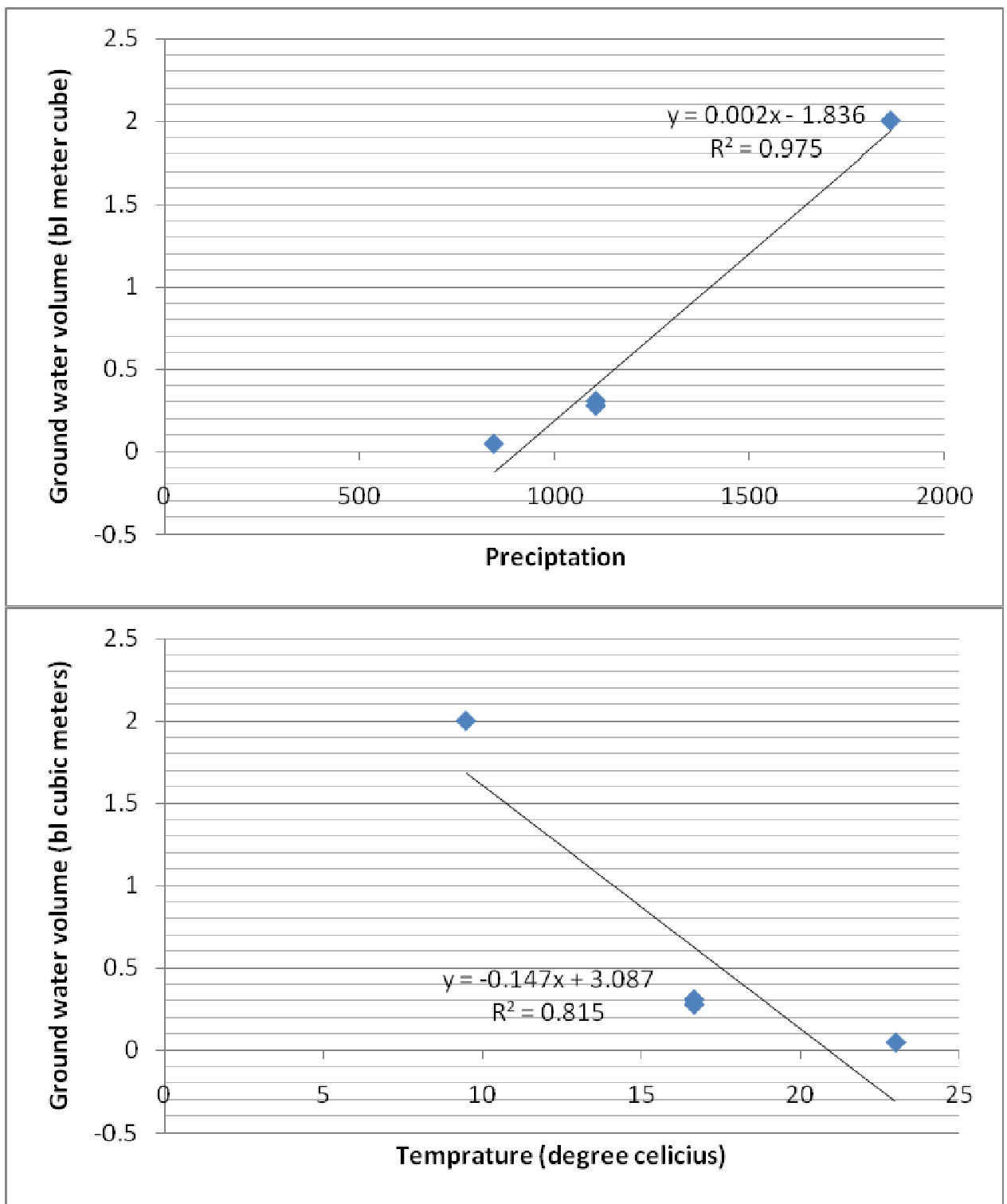

Figure 6: Sensitivities of ground water volume to climatic variables

The response of ground water volume across regions was significantly $(\mathrm{P}<0.01)$ negative as it declined with increases in temperature (Figure 6). The model's best fit line explained more than $81 \%$ of the variation in the data set observed for ground water volume across regions.
The Effect of Temperature on Precipitation

The amount of rainfall that had fallen across the four regions of Ethiopia was significantly $(\mathrm{P}<0.01)$ explained as a function of temperature (Figure 7). As the climate warmed the amount of precipitation declined significantly. The model's best fit explained more than $91 \%$ 


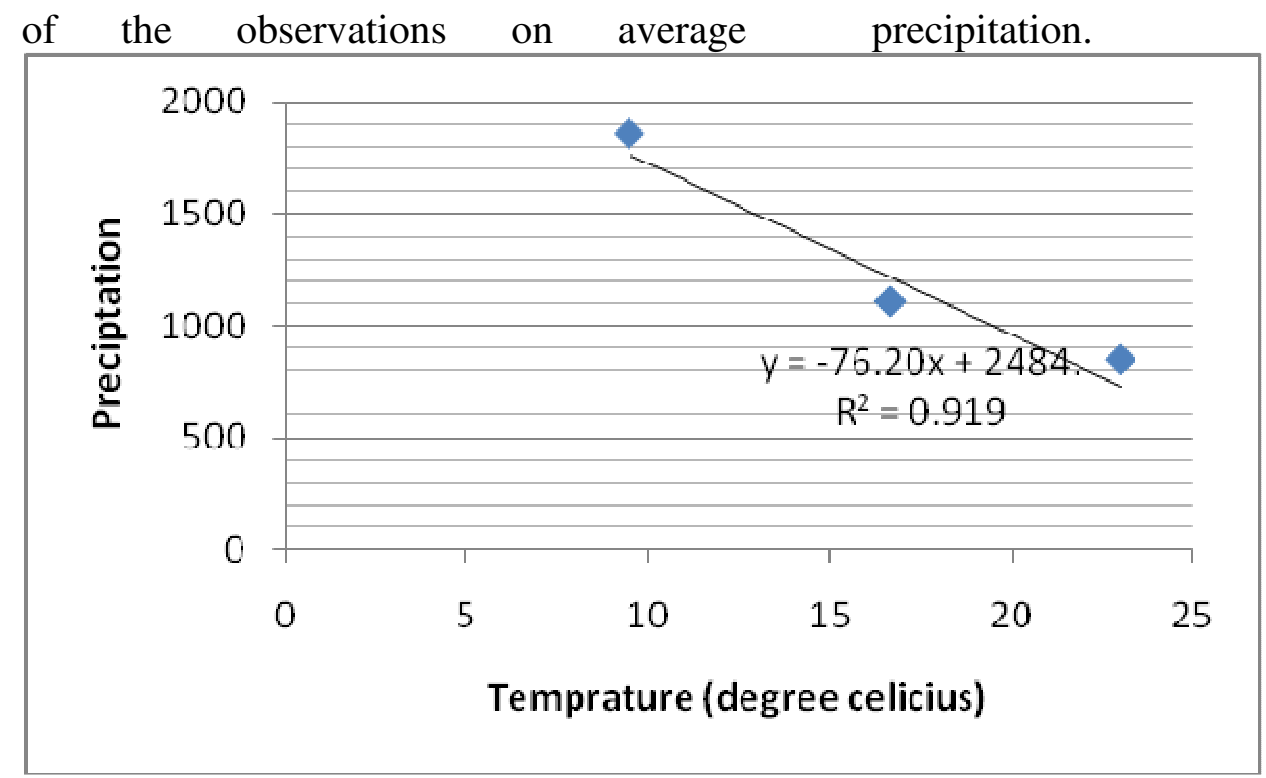

Figure 7: The effect of temperature on the average precipitation across the four regions

\section{Discussion}

Evidence regarding the substantial economic benefits gained by humans by maintaining biodiversity has been presented by various workers around the world (Constanza et al., 1997; de Groot et al., 2002; de Groot et al., 2010; Shimelis in press). These indicated through regulatory and other functions biodiversity plays very critical roles such as the maintenance of a healthy climate, the hydrological cycle and highly interrelated to these have significant contributions to the food production sector not to mention benefits accrued in the building of human shelters and also the consumptive use of plant and animal biomass as fuel.

In this paper one very important question regarding the functional role of forests was answered through the depiction of their effects on two key climatic variables which are precipitation and temperature. The variabilities in averages of these two response variables which was demonstrably proved as a function of differences in forest cover across the four regions of Ethiopia can explain why forests are considered as key for boosting food production and also mitigation of the calamities predicted to occur as result of the warming of the climate.

Agriculture is one of the most important economic sector most vulnerable to the calamities of a changing climate because of its natural sensitivities to key attributes of the latter (Smit and Skinner, 2002). Through regulation of key climatic components, as depicted in this paper, forests contribute significantly in making sure the right environment is created for food production which would be negatively affected in a significant manner if the climate warms. It was shown that such an effect is responsible for availability of ground and surface water which is dependent on the magnitude of precipitation and how warm the climate is. Thus one of the threats posed by climatic warming is the drying of our rivers which are major reservoirs of the surface water and also the emptying of wells which harbor waters of multiple uses to humans. 
The warming of the climate was also proven in this paper as the main driver of how high or low precipitation at the scale considered. This simply says as the climate gets warmer there will be substantial decline in rainfall. It is thus inevitable that deforestation brings about further warming of the climate at least at the scale considered in this paper along with all the calamities discussed with support of the evidence presented in this paper. Thus the concluding message is stop deforestation which is an anthropogenic process that causes the shrinkage of pristine landscapes that ought ways their natural potential to expand.

\section{Conclusion}

The results in the paper indicated forests regulate climate and because of that they affect food production including water availability. The line of thinking justified because of the evidence presented is rather than destroying pristine landscapes for the sake of a boost in food production what we need to do is expanding them wherever possible. This not only results in positive changes in food production but significantly reduces the likelihood of the climate warming which reduces productivity in a key economic sector.

\section{References}

Awulachew, S.B., Yilma, A.D., Loulseged, M., Loiskandl, W., Ayana, M. and Alamirew, T. (2007). Water Resources and Irrigation Development in Ethiopia. Colombo, Sri Lanka: International Water Management Institute. 78p. (Working Paper 123)

Constanza R., Wilson, M.A., Troy, A., Voinov, A. and Liu, S. (2006). The
Value of New Jersey's Ecosystem Services and Natural Capital. New Jersey Department of Environmental Protection

de Groot, S.R., Willson, A. M. and Bouman, J.M.R. 2002. A typology for the classification, description and valuation of ecosystem functions, goods and services. Ecological Economics, 41 : 393-408

de Groot, S.R., Alkemade, R., Braat, L., Hein, L. and Willemen, L. (2010). Challenges in integrating the concept of ecosystem services and values in landscape planning, management and decision making. Ecological Complexity.

Ehui, S., Paulos, Z., Solomon, A., Benin, S., Gebremedhin, B., Jabbar, M. and Pender, J. (2001). Interregional comparisons of agricultural production efficiency in the Ethiopian highlands. International Livestock Research Institute (ILRI). Ethiopia

Ethiopian Wildlife and Natural History Society. (2001). Ethiopia in Important Bird Areas of Arica and Related Islands. BirdLife International.

Karl, T.R., Jones, P.D., Knight, R.W., Kukla, G. and Plummer, N. (1993). Asymmetric Trends of Daily Maximum and Minimum Temperature. Papers in Natural Resources.

Smit, B. and Skinner, M. W. (2002). Adaptation Options to Climate Change: A Typology. Mitigation and Adaptation Strategies for Global Change.

Shimelis, A., Allport, G., Atkins, J., Fishpool, L., Wondafrash, M., Robertson, P., Demissew, S., Dejene, 
S., Edwards, S., Wolde Mariam, T., Nigussie, T. and Dellelegn, Y. (1996). Important Bird Areas of Ethiopia: A first inventory. Ethiopian Wildlife and Natural History Scoiety. Shimelis, A. (2016). Ecosystem Functions and Services of Cloud Afromontane Forests in Ethiopia. Ethiopian Journal of Environmental Studies and Management. 9(Suppl. 1): 928937.
Sutherland, W.J., Clout, M., Cote, I.M., Daszak, P., Depledge, M.H., Fellman, L., Fleishman, E., Garthwaite, R., Gibbons, D. W., De Lurio, J., Impey, A.J., Lickorish, F., Lindenmayer, D., Madgwick, J., Margerison, C., Maynard, T., Peck, L.S., Pretty, J., Prior, S., Redford, K.H., Scharlemann, J.P.W., Spalding, M. and Watkinson, A.R. (2010). A horizon scan of global conservation issues for 2010. Cel Press. 